\title{
Realistic Specific Power Expectations for Advanced Radioisotope Power Systems
}

\author{
Lee S. Mason ${ }^{*}$ \\ NASA Glenn Research Center, Cleveland, OH 44135
}

\begin{abstract}
Radioisotope Power Systems (RPS) are being considered for a wide range of future NASA space science and exploration missions. Generally, RPS offer the advantages of high reliability, long life, and predictable power production regardless of operating environment. Previous RPS, in the form of Radioisotope Thermoelectric Generators (RTG), have been used successfully on many NASA missions including Apollo, Viking, Voyager, and Galileo. NASA is currently evaluating design options for the next generation of RPS. Of particular interest is the use of advanced, higher efficiency power conversion to replace the previous thermoelectric devices. Higher efficiency reduces the quantity of radioisotope fuel and potentially improves the RPS specific power (watts per kilogram). Power conversion options include Segmented Thermoelectric (STE), Stirling, Brayton, and Thermophotovoltaic (TPV). This paper offers an analysis of the advanced 100 watt-class RPS options and provides credible projections for specific power. Based on the analysis presented, RPS specific power values greater than $10 \mathrm{~W} / \mathrm{kg}$ appear unlikely.
\end{abstract}

\section{Nomenclature}

$\mathrm{T}_{\mathrm{H}} \quad=$ power conversion hot-end temperature $(\mathrm{K})$

$\mathrm{T}_{\mathrm{C}} \quad=$ power conversion cold-end temperature $(\mathrm{K})$

$\mathrm{P}_{\mathrm{E}} \quad=$ net RPS electrical power $\left(\mathrm{W}_{\mathrm{e}}\right)$

$\eta_{\mathrm{S}} \quad=$ total RPS (system) efficiency

$\mathrm{Q}_{\mathrm{H}} \quad=$ total RPS heat input $=\mathrm{P}_{\mathrm{E}} / \eta_{\mathrm{S}}\left(\mathrm{W}_{\mathrm{t}}\right)$

$\mathrm{Q}_{\mathrm{R}} \quad=$ total RPS waste heat load $=\mathrm{Q}_{\mathrm{H}}-\mathrm{P}_{\mathrm{E}}\left(\mathrm{W}_{\mathrm{t}}\right)$

$\sigma=$ Stefan-Boltzmann constant $\left(5.67 \times 10^{-8} \mathrm{~W} / \mathrm{m}^{2}-\mathrm{K}^{4}\right)$

$\varepsilon \quad=$ radiator surface emissivity

$\eta_{\mathrm{F}} \quad=$ radiator fin effectiveness

$\mathrm{T}_{\mathrm{S}} \quad=$ radiator equivalent sink temperature $(\mathrm{K})$

$\mathrm{A}_{\mathrm{R}} \quad=$ total RPS radiator area $=\mathrm{Q}_{\mathrm{R}} /\left[\sigma \varepsilon \eta_{\mathrm{F}}\left(\mathrm{T}_{\mathrm{C}}{ }^{4}-\mathrm{T}_{\mathrm{S}}{ }^{4}\right)\right]\left(\mathrm{m}^{2}\right)$

$\mathrm{m}_{\mathrm{R}} \quad=$ RPS two-sided radiator mass $=5\left(\mathrm{~A}_{\mathrm{R}} / 2\right)(\mathrm{kg})$

$\mathrm{N}_{\mathrm{M}} \quad=$ number of GPHS modules $=\mathrm{Q}_{\mathrm{H}} / 250$

$\mathrm{m}_{\mathrm{HS}} \quad=$ total RPS heat source mass $=1.61 \mathrm{~N}_{\mathrm{M}}+3.01 \mathrm{~N}_{\mathrm{M}}^{0.455}(\mathrm{~kg})$

\section{Introduction}

$\mathrm{R}$ adioisotope Power Systems (RPS) are being considered for a wide range of future NASA space science and exploration missions. Some candidate missions include Mars Science Laboratory (MSL), Europa Orbiter, Solar Probe, and Robotic Lunar Exploration Program-2 (RLEP-2). As the Vision for Space Exploration is implemented, it is quite possible that RPS will be utilized for the human lunar outpost as a general utility power source. RPS could also be coupled with electric propulsion (Radioisotope Electric Propulsion or REP) to reduce the launch mass, decrease the trip time, or increase the payload mass for some outer planet science missions.

RPS are a popular choice for NASA missions because of their advantages over the alternative space power options (e.g. solar arrays, batteries, etc). RPS offer high reliability, long life and predictable power production regardless of operating environment. RPS design life can easily exceed 10 years, due in part to the use of wellknown materials, rigorous component testing, and a Pu-238 heat source with an 87.7 year half-life. A major motivation for using RPS on NASA missions is their ability to produce continuous, reliable electrical power in

\footnotetext{
${ }^{*}$ Senior Research Engineer, Thermal Energy Conversion Branch, MS301-2, AIAA Member
} 
remote and often severe environments, with no reliance on sunlight. Some of the past NASA missions to the outer planets could not have been performed without RPS, and some spacecraft continue to operate far beyond their original expectation due in part to the long life RPS.

The use of RPS in past NASA missions is well documented with Ref. 1 providing a good summary. Among the successful missions that have used RPS are Apollo, Viking, Voyager, and Galileo. All of the past RPS designs were Radioisotope Thermoelectric Generators (RTGs). The Apollo RTGs used lead-telluride ( $\mathrm{PbTe}$ ) thermoelectric devices and produced about 70 watts each with a system specific power of about $2 \mathrm{~W} / \mathrm{kg}$. The Viking RTG used $\mathrm{PbTe}$ and TAGS (a solid solution of tellurium, antimony, germanium, and silver) thermoelectric converters and produced about 40 watts with a specific power of about $3 \mathrm{~W} / \mathrm{kg}$. The Voyager mission used the Multi-Hundred Watt (MHW) RTG with silicon-germanium (SiGe) thermoelectric materials that produced about 160 watts at 4 W/kg. The Galileo mission used the General Purpose Heat Source (GPHS) RTG with SiGe thermoelectric converters, producing about 300 watts at $5 \mathrm{~W} / \mathrm{kg}$. The GPHS-RTG represents the current state-of-the-art RPS design configuration.

Today, NASA and DOE are evaluating design options for the next generation RPS ${ }^{2}$, as shown in Figure 1. The Multi-Mission Radioisotope Thermoelectric Generator (MMRTG) is being developed by Pratt \& Whitney and Teledyne Energy Systems for the DOE. The design is flexible to permit operation in either the vacuum of deep space or in partial atmosphere on planetary surfaces, a feature that has not been available in previous RTGs. It is derived from the Viking RTG with PbTe/TAGS thermoelectric converters and provides about 125 watts (Beginning of Mission or BOM) at $2.8 \mathrm{~W} / \mathrm{kg}$. Up until recently, DOE was also developing the Stirling Radioisotope Generator (SRG110) with Lockheed Martin and Infinia Corporation. The SRG110 was also designed for deep space and planetary surface missions, providing about 116 watts $(\mathrm{BOM})$ at $3.6 \mathrm{~W} / \mathrm{kg}$. A primary difference between the two options is the Pu-238 fuel inventory with the SRG110 using one-fourth the fuel of the MMRTG. The SRG110 project has been redirected by NASA and DOE in favor of developing an advanced Stirling design that provides greater efficiency and higher specific power.

NASA has also invested in several advanced power conversion technologies for potential use in future RPS under a competed Power Conversion Technology program ${ }^{3}$. However, most of these activities were de-scoped or terminated due to budget reductions. Among the technologies that received development funding by NASA were Advanced Stirling by Sunpower Inc., Segmented Thermoelectric (STE) by Teledyne Energy Systems, Thermophotovoltaic (TPV) by Creare Inc. and Edtek Inc, and Brayton by Creare Inc. Some of the performance projections associated with these advanced concepts are presented later in this paper.

It is important that power conversion down-select decisions and technology investments be made on sound judgment and practical performance expectations. In the past, some concept advocates have made extremely optimistic performance claims. This paper examines the mass of the heat source and radiator as a fundamental limit on RPS specific power. The heat source and radiator are predominantly influenced by two key RPS parameters: system efficiency and cold-end temperature.

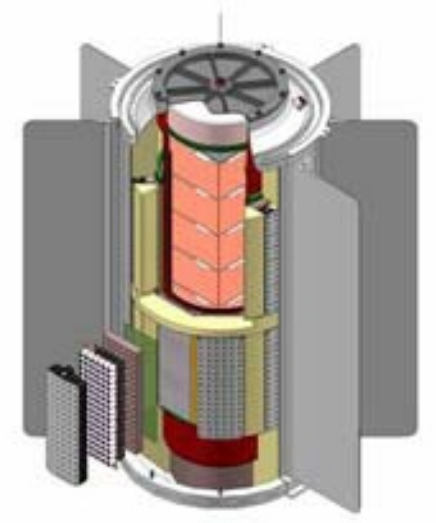

(a) MMRTG

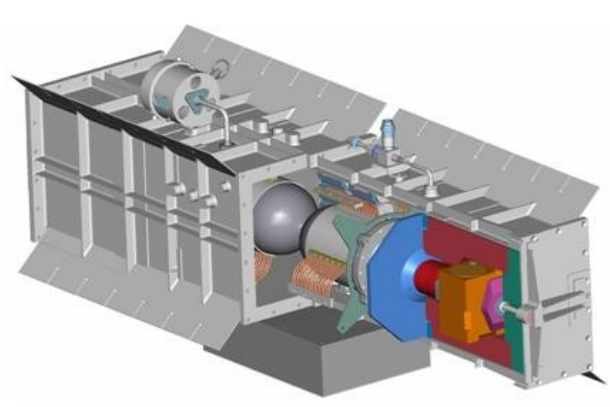

(b) SRG110

Figure 1. Near-term, next generation RPS options. Multi-Mission Radioisotope Thermoelectric Generator by Pratt \& Whitney and Teledyne (courtesy of Teledyne Energy Systems), Stirling Radioisotope Generator by Lockheed Martin and Infinia (courtesy of Lockheed Martin). 


\section{State-of-the-Art}

Table 1 shows the performance and mass of the GPHS-RTG, MMRTG, and SRG110. The three systems provide a good foundation for projecting advanced RPS performance. All of these systems have been subjected to thorough design analyses, numerous independent technical reviews, and extensive development testing. The component mass values are based on detailed designs and as-built hardware. The various components in the mass summary of Table 1 are generally applicable to any RPS.

Specific power, defined as BOM net electrical power divided by total mass, is a key performance metric for RPS. Higher values permit a greater amount of power to be delivered for a given mass allocation, or allow extra mass to be utilized for other spacecraft elements. The historical review shows a steady increase in specific power with each RPS design series. There are reasons to explain why the MMRTG and SRG110 appear to break this trend. The higher specific power for the GPHS-RTG is attributed to several factors including: 1) higher power level provides some economy-of-scale, 2) vacuum-only design with no features to permit operation in planetary atmospheres, and 3) the GPHS modules used were a lower mass version preceding a recent design update. As evident in Table 1, the mass of the GPHS-RTG is dominated by the heat source. In addition to the heat source, the MMRTG also has a large mass fraction attributed to the housing and radiator. In contrast, the SRG110's largest mass fraction is represented by the power conversion and electrical controls.

The RPS efficiency reported in Table 1 is the total end-to-end efficiency accounting for thermal insulation losses, power conversion efficiency, and power conditioning losses. The two thermoelectric systems have an efficiency of about $6 \%$ and the Stirling system provides just over 23\%. While the efficiency of the GPHS-RTG and MMRTG are similar, the operating temperatures are very different. The GPHS-RTG is a high temperature system matched to the optimum operating temperatures of the SiGe thermoelectric devices. The PbTe/TAGS thermoelectric converters for the MMRTG optimize at lower operating temperatures where the materials are more stable. In general, the RPS efficiency is proportional to the converter temperature ratio $\left(T_{H} / T_{C}\right)$ according to the converter's characteristic fraction-of-Carnot. Of the three systems, the SRG110 has the highest system level fraction-of-Carnot at about $36 \%$ while the GPHS-RTG has the lowest at $12 \%$. The total RPS heat input $\left(\mathrm{Q}_{\mathrm{H}}\right)$, defined as the net electrical power $\left(\mathrm{P}_{\mathrm{E}}\right)$ divided by the RPS efficiency $\left(\eta_{\mathrm{S}}\right)$, determines the required number of GPHS modules and the corresponding mass of the RPS heat source.

The cold-end temperature and system efficiency determines the radiator area and the corresponding mass of the RPS radiator. Radiator area is proportional to the waste heat load $\left(\mathrm{Q}_{\mathrm{H}}-\mathrm{P}_{\mathrm{E}}\right)$ and inversely proportional to cold-end temperature $\left(\mathrm{T}_{\mathrm{C}}\right)$ to the fourth power according to the Stefan-Boltzmann radiation heat transfer equation. The radiator area estimates in Table 1 are calculated based on an assumed surface emissivity $(\varepsilon)$ of 0.85 , fin effectiveness $\left(\eta_{\mathrm{F}}\right)$ of 0.8 , and sink temperature $\left(\mathrm{T}_{\mathrm{S}}\right)$ of $-70^{\circ} \mathrm{C}$. These parameters are reasonable for a typical finned-housing RPS mounted on a spacecraft boom in an earth orbital environment (i.e. at BOM). The GPHS-RTG has the lowest radiator area per unit power as a result of the high $300^{\circ} \mathrm{C}$ cold-end temperature. Despite similar efficiency, the MMRTG has over twice the radiator area per unit power as the GPHS-RTG, a direct consequence of the $90^{\circ} \mathrm{C}$ reduction in cold-end temperature. The SRG110 has the lowest cold-end temperature at $80^{\circ} \mathrm{C}$, but compensates for the low temperature with an efficiency that is almost four times as high as the thermoelectric systems.

Table 1. State-of-the-art RPS. Comparing existing GPHS-RTG with near-term MMRTG and SRG110.

\begin{tabular}{|l|c|c|c|}
\hline & GPHS-RTG & MMRTG & SRG110 \\
\hline BOM Net Electrical Power, $\mathrm{W}_{\mathrm{e}}$ & 285 & 125 & 116 \\
\hline Hot-end Temperature, ${ }^{\circ} \mathrm{C}$ & 1000 & 538 & 650 \\
\hline Cold-end Temperature, ${ }^{\circ} \mathrm{C}$ & 300 & 210 & 80 \\
\hline No. GPHS Modules & 18 & 8 & 2 \\
\hline BOM Heat Input, $\mathrm{W}_{\mathrm{t}}$ & 4500 & 2000 & 500 \\
\hline RPS (System) Efficiency & $6.3 \%$ & $6.3 \%$ & $23.2 \%$ \\
\hline Approx. Radiator Area, $\mathrm{m}^{2} / \mathrm{kW}_{\mathrm{e}}$ & 3.6 & 7.4 & 6.2 \\
\hline GPHS Modules, $\mathrm{kg}$ & 25.7 & 12.9 & 3.2 \\
\hline Heat Source Support, $\mathrm{kg}$ & 4.7 & 2.8 & 0.3 \\
\hline Heat Distribution, $\mathrm{kg}$ & - & 2.7 & 0.6 \\
\hline Thermal Insulation, $\mathrm{kg}$ & 6.4 & 2.4 & 3.2 \\
\hline Power Conv. \& Elect. Controls, $\mathrm{kg}$ & 6.2 & 9.7 & 16.7 \\
\hline Housing \& Radiator Fins, $\mathrm{kg}$ & 13.0 & 13.7 & 8.5 \\
\hline Total Mass, kg & 56.0 & 44.2 & 32.5 \\
\hline Specific Power, W/kg & 5.1 & 2.8 & 3.6 \\
\hline
\end{tabular}




\section{A. The Total Heat Source}

A common misconception is that the RPS heat source is comprised only of GPHS modules. In fact, the GPHS modules must be combined with other RPS components to permit efficient heat transfer to the power conversion devices, to minimize heat losses, and to maintain structural integrity during launch and/or inadvertent reentry. All of the systems in Table 1 assume the flightqualified GPHS module which produces about $250 \mathrm{~W}_{\mathrm{t}}(\mathrm{BOM})$. An updated version of the GPHS is anticipated for the MMRTG and SRG110 that will increase the mass from $1.43 \mathrm{~kg}$ to $1.61 \mathrm{~kg}$ per module, but improve the reentry and impact survivability ${ }^{4}$. Interestingly, this GPHS module mass increase would have decreased the GPHSRTG specific power from $5.1 \mathrm{~W} / \mathrm{kg}$ to $4.8 \mathrm{~W} / \mathrm{kg}$.

The overall mass of the RPS heat source is attributed to four components: GPHS modules, heat source support, heat distribution, and thermal insulation. When combined, these four components account for $66 \%$ of the GPHS-RTG mass, $47 \%$ of the MMRTG, and $23 \%$ of the SRG110. Figure 2 shows the total RPS heat source mass and the relative portions of GPHS and balance of heat source versus the number of GPHS modules. For the 18-module GPHS-RTG, the ratio of total heat source mass to GPHS mass is about 1.4. The two-module SRG110 has a total heat source mass to GPHS mass ratio of 2.3. From Figure 1, a curve fit is derived for the balance of heat source mass as a function of the number of GPHS modules $\left(\mathrm{N}_{\mathrm{M}}\right)$. This permits the total RPS heat source mass $\left(\mathrm{m}_{\mathrm{HS}}\right)$ to be expressed as the sum of the GPHS modules and the balance of heat source.

\section{B. Radiator Sizing}

As stated earlier, the RPS radiator area is dependent on system efficiency and cold-end temperature. Figure 3 shows representative curves of radiator area per unit power for cold-end temperatures of $0,50,100$, and $300^{\circ} \mathrm{C}$. The curves assume the same design parameters stated previously: 0.85 emissivity, 0.8 fin effectiveness, and $-70^{\circ} \mathrm{C}$ sink temperature. As the figure indicates, there are two approaches to minimize radiator area: 1) low efficiency with high cold-end temperature, or 2) high efficiency with moderate cold-end temperature. Cold-end temperatures of $0^{\circ} \mathrm{C}$ and below result in unreasonably large radiators. While the use of ultra-lightweight radiator materials could minimize the mass penalty associated with a large radiator, the excessive size makes the RPS impractical from a spacecraft integration perspective. Many of the advanced power conversion technologies project high efficiency. Often times the high efficiency is the direct result of assuming an inappropriately low, cold-end temperature.

There are many factors which determine the mass of the RPS radiator. The three systems in Table 1 utilize radiator surfaces that share functionality with housing structure. For the thermoelectric systems, the housing is cylindrical with axial radiator fins that are attached around the circumference. The SRG110 uses a rectangular housing with axial fins that are attached at the corners. In all of these systems, the housing and fins combine to provide the radiator surface. Based on the housing/radiator masses and estimated radiator areas in Table 1, the areal mass of the combined housing/radiator structure ranges from about $15 \mathrm{~kg} / \mathrm{m}^{2}$ for MMRTG to about $12 \mathrm{~kg} / \mathrm{m}^{2}$ for the GPHS-RTG and SRG110.

The use of a flat panel, two-sided radiator could potentially reduce the areal mass and improve RPS specific power. A typical flat panel radiator might consist of a lightweight core with tubular heat pipes sandwiched between two thin facesheets as shown in Figure 4. The areal mass, defined as total panel mass divided by one-sided area, would depend on the panel thickness and materials of construction. For a $1 \mathrm{~cm}$ thick panel, the areal mass would vary from $2.4 \mathrm{~kg} / \mathrm{m}^{2}$ for $0.5 \mathrm{~mm}(20 \mathrm{mil})$ thick composite facesheets and a reticulated vitreous carbon (RVC) core to $5.6 \mathrm{~kg} / \mathrm{m}^{2}$ for $0.8 \mathrm{~mm}$ (32 mil) aluminum facesheets and an aluminum honeycomb core. The two different facesheet 
thicknesses provide essentially the same fin effectiveness given the variation in the two material's through-thickness thermal conductivity. The addition of intermittently spaced heat pipes (e.g. $\mathrm{Cu}-\mathrm{H}_{2} \mathrm{O}, \mathrm{Al}-\mathrm{NH}_{3}$, or Ti$\mathrm{H}_{2} \mathrm{O}$ ) in the panel would increase the areal mass.

For projecting RPS mass, a notional $1 \mathrm{~cm}$ thick, two-sided radiator panel using composite facesheets, honeycomb core, and titanium heat pipes is estimated to have a one-sided areal mass of $5 \mathrm{~kg} / \mathrm{m}^{2}$. Since the two-sided, flat panel radiator cannot provide dual functionality as the RPS housing, additional mass must be allocated for integration structure when projecting RPS specific power with this radiator approach.

\section{Specific Power Limits}

The heat source and radiator provide fundamental limits on RPS specific power. Given the heat source mass scaling relationship, radiator sizing approach, and radiator areal mass assumption discussed in Section II, one could generate a set of enveloping curves for RPS specific power.

Figure 5 presents specific power curves for the heat source and radiator as a function of efficiency and cold-end temperature for a 100 watt-class RPS. The upper dashed curve

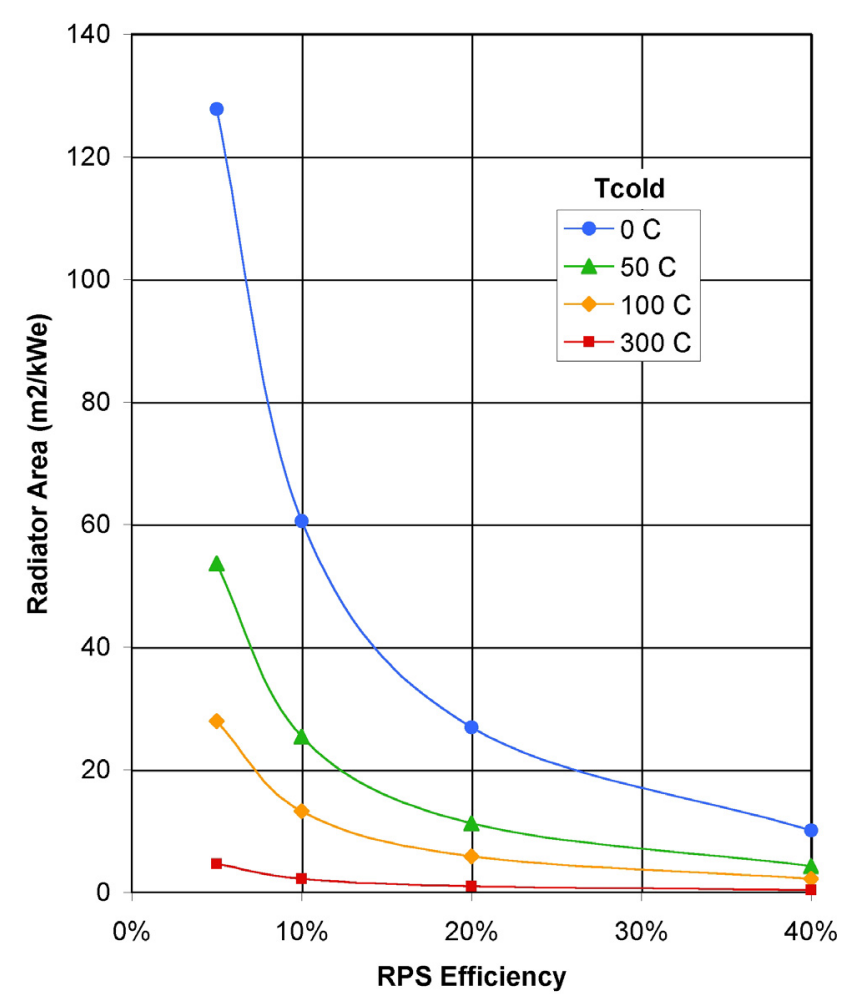

Figure 3. Radiator area trends. Radiator area is minimized by high cold-end temperatures or high efficiency. represents the mass of the heat source only: GPHS modules, support structure, heat distribution, and thermal insulation. The underlying curves represent the addition of the radiator mass for varying cold-end temperatures ranging from $300^{\circ} \mathrm{C}$ to $0^{\circ} \mathrm{C}$. These curves provide practical maximum limits for RPS specific power. For example, a hypothetical $20 \%$ efficient RPS with a $50^{\circ} \mathrm{C}$ coldend would have a maximum specific power of $10 \mathrm{~W} / \mathrm{kg}$ based on the heat source and radiator only. The addition of mass for power conversion equipment, electrical controls, and integration structure would reduce the specific power to values less than $10 \mathrm{~W} / \mathrm{kg}$.

For the thermoelectric and TPV systems, the additional mass might be small given the relatively lightweight power conversion devices and minimal power electronics needed. For Stirling and Brayton systems, the additional mass could be greater based on the higher mass, mechanical power converters and associated power electronics to provide standard DC bus power.

\section{A. Power Conversion Technology Mapping}

The curves in Figure 5 provide a context for bounding RPS specific power levels as a function of efficiency and cold-end temperature. The various power conversion technologies could be mapped onto this graphic based on their characteristic performance attributes. Thermoelectric systems tend to have system efficiencies in the range from $5 \%$ to $15 \%$ with corresponding cold-end temperatures of $300^{\circ} \mathrm{C}$ and $50^{\circ} \mathrm{C}$, respectively. The $5 \%$ efficient, $300^{\circ} \mathrm{C}$ system is representative of $\mathrm{SiGe}$ thermoelectric devices while the $15 \%$ efficient, $50^{\circ} \mathrm{C}$ system is representative of some of the advanced skutterudite converters under development by JPL. TPV systems are projected to have efficiencies ranging from $15 \%$ efficiency at $50^{\circ} \mathrm{C}$ cold-end to $25 \%$ at $0^{\circ} \mathrm{C}$. A

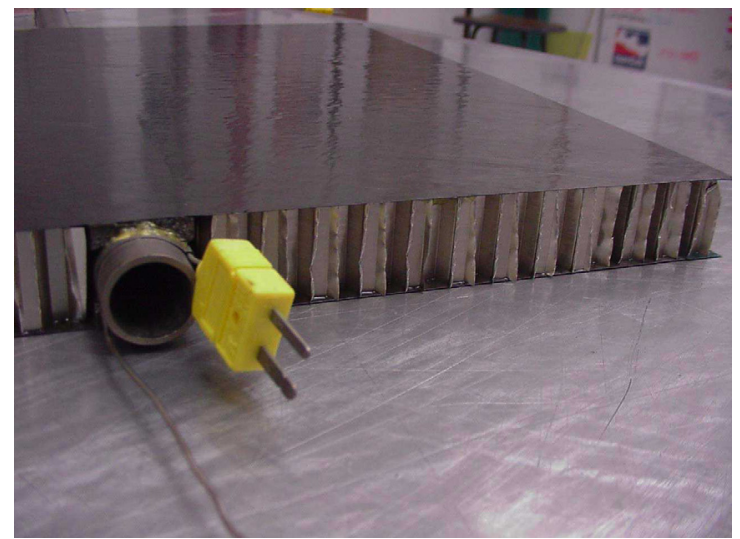

Figure 4. Example of two-sided honeycomb radiator with composite facesheets and titanium heat pipe tube. Photograph courtesy of Advanced Cooling Technologies, Inc. 
majority of the TPV designs that have been developed to date assume room temperature solar cells resulting in cold-end temperatures of about $25^{\circ} \mathrm{C}$. Stirling and Brayton systems tend to exhibit similar performance characteristics with efficiencies that range from about $20 \%$ at $100^{\circ} \mathrm{C}$ cold-end temperature to $35 \%$ at $0^{\circ} \mathrm{C}$. The high efficiencies with dynamic power conversion result from the heat engine's ability to achieve an intrinsically high fraction-of-Carnot.

Figure 6 presents some images of candidate advanced power conversion devices that were being pursued under the NASA Power Conversion Technology program introduced previously $^{3}$. The advanced Stirling convertor by Sunpower Inc. was projected to provide at least 8 $\mathrm{W} / \mathrm{kg}$ and $30 \%$ efficiency at the system level. The STE option by Teledyne Energy Systems had system-level goals of $5 \mathrm{~W} / \mathrm{kg}$ and $10 \%$ efficiency. There were two different contractors developing TPV technology. Creare Inc. was projecting their TPV system at $15 \mathrm{~W} / \mathrm{kg}$ and up to $20 \%$ efficiency, while Edtek Inc. was estimating $8 \mathrm{~W} / \mathrm{kg}$ and up to 23\% efficiency. The Brayton RPS concept by Creare Inc. was projecting system specific power levels of at least $9 \mathrm{~W} / \mathrm{kg}$ at efficiencies of $25 \%$. It should be noted that these system performance projections are "as advertised" by the organization developing the design concept and have not been independently verified by a nonadvocate party.

\section{B. Realistic Projections}

Figure 7 presents a revised version of Figure 5 with the power conversion technology ranges denoted in the colored regions and the various system designs identified by circular markers. The technology ranges are defined by the characteristic performance attributes discussed previously and the specific power curves generated for the heat source and radiator mass. Since the upper boundary of these ranges represents the heat source and radiator mass only, the realistic RPS design space should fall well below these limits.

The markers represent RPS designs based on their "advertised" efficiency and specific power. The filled markers are the two near-term options that were defined in Table 1, and both fall well within the indicated technology ranges. The GPHS-RTG is not shown since the $285 \mathrm{~W}_{\mathrm{e}}$ power level puts it outside the reasonable range of the 100 watt-based specific power curves. The open markers show some of the advanced RPS options. While most of the markers fall within the defined technology ranges, they are generally located in the upper portion of the

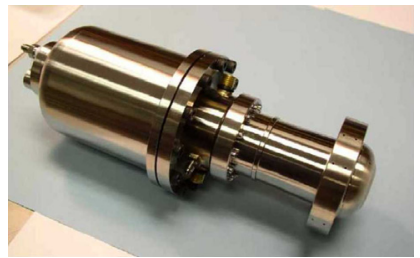

(a) Stirling Convertor

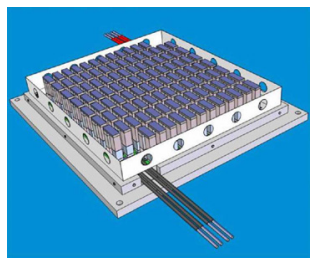

(b) STE Module

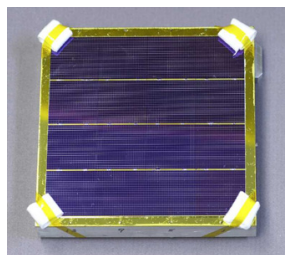

(c) TPV Array

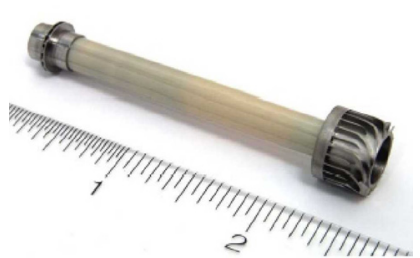

(d) Brayton Rotor

Figure 6. Advanced Power Conversion Technologies. Advanced Stirling Convertor by Sunpower Inc. (Athens, OH), Segmented Thermoelectric Module by Teledyne Energy Systems (Hunt Valley, MD), Thermophotovoltaic Array by Creare Inc. (Hanover, NH), and Brayton Rotor by Creare Inc. (Hanover, NH). 
design space. This may indicate that the designs are somewhat optimistic with regard to specific power. The Sunpower Stirling design appears to be the most credible with sufficient margin from the upper boundary to account for mass associated with the power conversion, electrical controls, and integration structure. The Creare TPV design appears to be outside the feasible design space based on the analysis presented here.

The various design envelopes provide a useful tool for projecting 100 watt-class RPS specific power. Given the relatively small mass addition for power conversion and electronics with the thermoelectric and TPV systems, it is conceivable that future designs could approach the top of the design envelopes. For thermoelectric systems, this would result in specific power values ranging from about 4 to $6 \mathrm{~W} / \mathrm{kg}$. For the higher efficiency TPV systems, the specific power range could be 5 to $7 \mathrm{~W} / \mathrm{kg}$. The dynamic system options appear to offer the greatest potential for high specific power. Based on the upper boundary of the Stirling/Brayton envelope and accounting for the larger mass allocation expected with the power conversion equipment and electronics, specific power values between 8 and $10 \mathrm{~W} / \mathrm{kg}$ appear practical. For any of these specific power values to be realized, NASA must maintain support in RPS power conversion technology development.

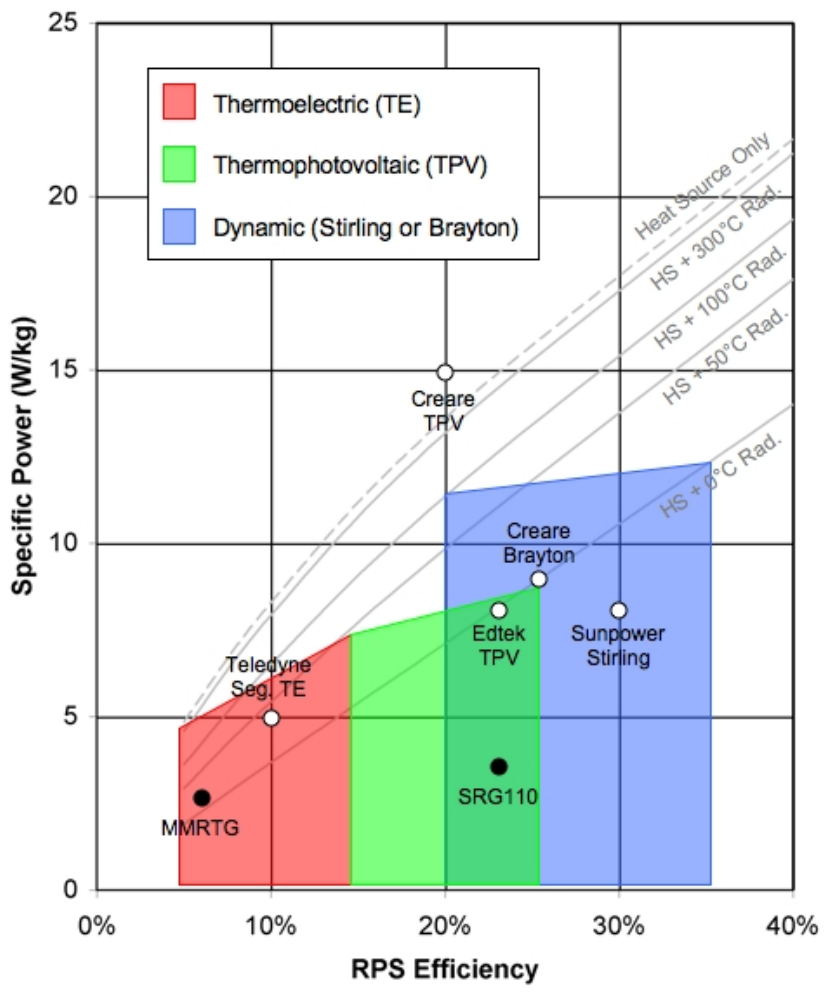

Figure 7. Expected $100 \mathrm{~W}_{\mathrm{e}}$ RPS Design Space. The colored regions represent the reasonable design envelopes for the various power conversion technologies.

\section{Conclusion}

RPS will undoubtedly be an element of future NASA science and exploration missions based on their appealing performance attributes and successful operational heritage. NASA is currently evaluating various design strategies to improve the specific power of the RPS through the use of advanced power conversion technologies. Careful judgment must be exercised when comparing design options and making decisions on technology investments. In certain cases, concept advocates may project performance beyond reasonable measures. This paper examined the heat source and radiator as a fundamental limit on RPS specific power. The study relied upon the current state-ofthe-art RPS as a foundation for projecting future RPS performance. The analysis considered many of the advanced power conversion technologies currently under study by NASA including Stirling, STE, TPV, and Brayton. The general conclusion from the analysis is that RPS specific power values greater than $10 \mathrm{~W} / \mathrm{kg}$ appear unrealistic.

\section{Acknowledgments}

The work described in this paper was performed for the NASA Prometheus Power and Propulsion Program. Any opinions, findings, and conclusions or recommendations expressed in this paper are those of the author and do not necessarily reflect the views of NASA.

\section{References}

${ }^{1}$ Hyder, A.K., Wiley, R.L., Halpert, G., Flood, D.J., and Sabripour, S., Spacecraft Power Technologies, Imperial College Press, London, 2000, Chaps. 5, 6.

${ }^{2}$ Schmidt, G.R., Wiley, R.L., Richardson, R.L., and Furlong, R.R., "NASA's Program for Radioisotope Power System Research and Development," AIP Proceedings, Volume 746, Feb. 2005, pp 429-436.

${ }^{3}$ Wong, W.A., "Advanced Radioisotope Power Conversion Technology Research and Development," NASA/TM-2004213352, Dec. 2004.

${ }^{4}$ Pantano, D.R., and Hill, D.H., "Thermal Analysis of Step 2 GPHS for Next Generation Radioisotope Power Source Missions," AIP Proceedings, Volume 746, Feb. 2005, pp. 827-834. 